\title{
Non-Repeatable Hedonism Is False
}

\author{
TRAVIS TIMMERMAN \\ Seton Hall University
}

FELIPE PEREIRA

Seton Hall University

\section{Introduction}

In his characteristically excellent paper, "A New Defense of Hedonism about Well-Being,"1 Ben Bramble provides a series of highly original arguments defending a new kind of hedonism. Specifically, Bramble argues for a hedonism that (1) adopts a felt-quality (as opposed to an attitude-based) theory of pleasure and pain $^{2}(\S 4),(2)$ makes use of an important distinction between "the degree to which a pleasure is pleasurable" and the "ease with which one can introspect it" (101), and, crucially, (3) holds that purely repetitious pleasures add no value to one's life $(\S 4)$. We'll refer to this third component of his view as the NonRepetition Requirement and any version of hedonism that adopts this requirement as a version of Non-Repeatable Hedonism. The Non-Repetition Requirement is what makes Bramble's hedonism unique, and it is the target of this paper. ${ }^{3}$

We pose a dilemma for Non-Repeatable Hedonism. We argue that it is either committed both to a deeply implausible asymmetry between how pleasures and pains affect a person's well-being and to deeply implausible claims about how to maximize well-being, or is committed to the claim that a life of eternal pleasure for a person can be just as good for them as a life of eternal suffering. The only way out of this dilemma is for Bramble to reject the Non-Repetition Require-

1. All in-text citations refer to Bramble's (2016) "A New Defense of Hedonism about WellBeing."

2. For a more robust version of this sort of argument, see Bramble's (2013).

3. Bramble also defends the non-repetition requirement in his (2015a: 455) and his (2015b: 206). In his (2018: 29-33), Bramble adds an additional unique component to his hedonism. He argues that hedonism cannot, and need not, make sense of temporal well-being.

Contact: Travis Timmerman <travis.timmerman@shu.edu> and Felipe Pereira <felipede queiroz.pereira@gmail.com> 
ment. Yet, rejecting this requirement both forces Bramble to reject the wholly unique, core component, of his view and undermines his view's ability to handle one of the most powerful objections to hedonism, viz., that a life with a larger quantity of so-called "base" (or lower) pleasures is better for a person than a life with a slightly smaller quantity of so-called higher pleasures.

This paper is organized as follows. In the next section, we provide an overview of Bramble's Non-Repeatable Hedonism. In doing so, we explain how his Non-Repetition Requirement is supposed to avoid the aforementioned objection to hedonism. In the third section, we present our dilemma for Non-Repeatable Hedonism and argue that the only viable option is to reject the Non-Repetition Requirement. Finally, we review the implications of rejecting the Non-Repetition Requirement for Bramble's hedonism.

\section{Bramble's Non-Repeatable Hedonism}

Bramble's hedonism grounds itself on the assumption that any adequate theory of well-being must satisfy what he refers to as "the Experience Requirement."

The Experience Requirement: Something can benefit or harm a being only if it affects her experiences in some way-specifically, their phenomenology (or 'what it is like' to be having them). (88) ${ }^{4}$

Insofar as death is typically understood to entail the permanent cessation of one's experiences, Bramble suggests that only pleasures and pains are up for consideration as potential ways to benefit or harm one's lifetime well-being (90). Pleasures and pains respect the Experience Requirement - they can only occur if someone is there, alive, to experience them. The same does not appear to be true of other candidates for intrinsic goods (e.g., success, fame, desire satisfaction). People can seemingly gain success, become famous, and have their desires satisfied even after death, which is to say, after they cease to have experiences altogether. Therefore, Bramble concludes that only a theory which measures the extent to which one's life is good in terms of pleasures and pains can be an adequate theory of well-being (89). This theory, of course, is hedonism. However, Bramble rejects traditional hedonism, instead proposing the following view.

4. This part of Bramble's argument will not be dialectically effective against non-hedonists who are either happy to accept that people can be posthumously harmed or wish to deny posthumous harm by appealing to the Existence Requirement instead of the Experience Requirement. For discussion, see McMahan (1998) and for an argument against the Experience Requirement, see Fischer (1997). 
For any two individuals, $\mathrm{S}$ and $\mathrm{S}^{*}, \mathrm{~S}$ was better off in some respect in her life considered as a whole than $S^{*}$ if and only if

$S$ felt some kind of pleasurable phenomenology that $S^{*}$ did not feel, or some kind of pleasurable phenomenology that $S^{*}$ felt, but in a higher degree than $S^{*}$ felt it, or

$S^{*}$ felt some kind of painful phenomenology that $S$ did not feel, or some kind of painful phenomenology that $S$ felt, but in a higher degree than $S$ felt it. (109-110)

There are a few important points to keep in mind about Bramble's hedonism. First, when discussing pleasures and pains, Bramble adopts a felt-quality theory of pleasures and pains. According to felt-quality theories, some experience counts as a pleasure or a pain simply in virtue of the way it feels to experience it, that is, in virtue of its phenomenology. Attitude-based theories, which are the alternative, posit that some experience counts as a pleasure or a pain simply in virtue of the attitude a subject has towards the experience. By adopting a felt-quality theory of pleasures and plains, Bramble wants to avoid the possibility that something may be considered a pleasure or a pain without changes in one's experience (9092). Attitude-based theories allow for the possibility that an agent changes her attitude towards an experience, thus changing the pleasure-pain status of that experience even if the experience itself remains the same. That possibility would suggest that the Experience Requirement is false, that there are in fact ways to alter one's lifetime well-being independent of one's experience.

Second, Bramble's hedonism is unique, in part, because he adds the NonRepetition Requirement in order to avoid the famous objection considered by J. S. Mill, and later rearticulated by Fred Feldman. Feldman conceives of a human named Porky, who lives the following kind of life.

Porky: Porky spends all his time in the pigsty, engaging in the most obscene sexual activities imaginable. [. . .] Porky derives great pleasure from these activities and the feelings they stimulate. Let us imagine that Porky happily carries on like this for many years. Imagine also that Porky has no human friends, has no other sources of pleasure, and has no interesting knowledge. Let us also imagine that Porky somehow avoids pains - he is never injured by the pigs, he does not come down with any barnyard diseases, he does not suffer from loneliness or boredom. (Feldman 2004: 40)

Unqualified traditional forms of hedonism entail the supposedly absurd conclusion that a life like Porky's (and a pig's life) could be better than a typical 
human life. This is for the simple reason that Porky's life (and a pig's life) could contain more net pleasure than a typical human life. Hedonism, therefore, must be false-or so the objection goes. One response Bramble gives, which is consistent with traditional hedonism, holds that "bodily pleasures like Porky's aren't especially pleasurable" (96). Such pleasure may be intense in the sense that they're easy to attend to, but not intense in the sense that they're intensely pleasurable. The pleasures that are intensely pleasurable are, on Bramble's view, "higher" pleasures such as love, learning, aesthetic appreciation, and so on (96).

Note, however, that this response alone is insufficient to avoid the Porky problem since the case can simply be amended to increase the quantity of "base" (not very pleasurable) pleasures Porky experiences until he has a greater net total of pleasures than the average human. Bramble, however, seems to believe that Porky's life would be worse than a typical human's life no matter how long Porky gets to experience the "base" pleasures of bestiality. To avoid this problem, Bramble builds the Non-Repetition Requirement into his hedonism.

Here is how Bramble formulates this essential component of his view. He first suggests that the "diversity in our pleasures has a special value for us" (109). According to him, the extent to which a pleasure introduces - or fails to introduce-value to a person's life is intimately related to the extent to which this pleasure is novel. If a pleasure is not qualitatively novel, then it supposedly bears no impact on a person's lifetime well-being. Let us call this the NonRepetition Requirement.

Non-Repetition Requirement: "Purely repeated pleasures - i.e., pleasures that introduce nothing qualitatively new in terms of pleasurableness into a person's life-add nothing in and of themselves to her lifetime wellbeing" (98).

Now, this requirement should not make us doubt the value of the continued enjoyment one receives from the "higher" pleasures. This is because there will typically be sufficient qualitative variation between such pleasures (e.g., love, knowledge acquisition, aesthetic appreciation) to make each typical individual experience of a higher pleasure contribute to one's total well-being. For instance, according to Bramble, "many qualitatively new pleasures $[\ldots]$ are made possible by friendships and relationships as they evolve or deepen over time" (98). Likewise, pleasures that arise from learning typically "have quite a different phenomenal character depending on what one has learned [ ...] and how one's knowledge [ ... ] fits with what one already knows," and how "one's enjoyment of a particular piece of music may itself deepen or evolve in wonderful ways over the courses of weeks, months, or even years" (98-99). That, according to Bramble, is the fundamental difference between intense, "higher" pleasures, and 
"base" pleasures. Whereas bodily pleasures "seem rapidly to become just more of the same," pleasures that arise from love, learning, or aesthetic appreciation are rich in qualitative diversity (99). Porky's life, according to his view, is worse than a typical human's life no matter how long Porky gets to experience the "base" pleasures of bestiality because the pleasures of bestiality are not qualitatively diverse (99).

It may be objected, as Bramble well acknowledges, that there are some seemingly purely repeated pleasures that appear to add some value to a person's lifetime well-being. "Is there really nothing of value for, say, Mary, in her enjoyment of her morning coffee, an enjoyment that presumably is qualitatively identical each time?" (99-100). Bramble insists, however, that such cases need not contradict his Non-Repetition Requirement. Each time Mary enjoys her coffee, there may be "subtly new elements" (e.g., the setting, the brand of coffee, the mug she's drinking from) that are sufficient for her experience to count as a qualitatively novel pleasure, and so sufficient for each instance of her drinking her morning coffee to contribute to her lifetime well-being (100).

One may worry that whatever slight qualitative differences Bramble appeals to in order to preserve the judgment that Mary's morning coffee is continually good for her will prove too much. After all, Porky's activities could be as qualitatively diverse as Mary's morning coffee. Bramble can't have his cake and eat it too. Or, more precisely, Bramble can't maintain that Mary's morning coffee is good for her without also allowing that Porky's carnal acts with pigs are good for him. We set this worry aside, however, because Bramble's Non-Repetition Requirement actually generates a much deeper, much more serious, problem for his hedonism. It is to this worry that we now turn.

\section{A Dilemma for Bramble's Non-Repeatable Hedonism}

When Bramble discusses the Non-Repetition Requirement, he only focuses on instances of purely repeatable pleasures. This raises the question of whether this requirement applies to pains as well. If it doesn't, then Bramble seems committed to an ad hoc asymmetry and some rather absurd conclusions. If it does, then Bramble is committed to an even more absurd conclusion, or so we argue. We'll discuss each horn in turn.

Horn 1 - Asymmetry: Suppose that Bramble argues that purely repeated pains do decrease one's total well-being. In this case, Bramble has to hold that the following two propositions are true. 
(P1) Purely repeated pleasures do not alter the value of one's life considered as a whole, for only non-repetitious pleasures do.

( $\left.\mathrm{P}_{2}\right)$ Purely repeated pains do alter the value of one's life considered as a whole, for they decrease one's well-being.

Yet, if purely repeated pains do alter one's lifetime well-being, then why is it the case that purely repeated pleasures don't? Asserting $\left(\mathrm{P}_{1}\right)$ and $\left(\mathrm{P}_{2}\right)$ without providing any principled reason to treat them differently would be to maintain an indefensible ad hoc asymmetry.

Were Bramble to opt for this horn, he would commit his hedonism to a very mysterious difference between pleasures and pains. 5 This being the case, Bramble seems to owe us an explanation for this mysterious difference. Yet, without one, this mysterious difference is either a brute fact or Bramble is wrong to assume that it exists. To accept this difference as a brute fact is hardly satisfying. If Bramble cannot offer an explanation for such a difference, then there is good reason to believe that there is no difference, and that repeated pleasures and pains should be treated symmetrically.

While positing this unexplained asymmetry is seriously problematic in its own right, it also creates additional problems for Bramble's view. Positing this asymmetry leads to radically counterintuitive consequences in various firstorder cases. For instance, it entails that maximizing well-being always requires preventing any amount of (repeated or non-repeated) pain over allowing any amount of repeated pleasure. This is absurd. To illustrate, suppose that you have the ability to either (i) prevent the tiniest pinprick that would be a repeated pain or (ii) ensure that everyone in the world receives an additional thirty years of repeated pleasures. On this horn of the dilemma, maximizing well-being requires preventing the pinprick. ${ }^{6}$ This is a surprising conclusion to say the least. Suppose that the person who faces the threat of a repeated pinprick is also a potential recipient of the thirty years of repeated pleasure. We imagine everyone, including the person facing the repeated pinprick or repeated thirty years of pleasure, would prefer the thirty years of repeated pleasure (and would think that this is what would maximize well-being). This judgment is hard to deny.

In light of this problem, Bramble might be inclined to opt for the second horn

5. Note that this asymmetry is much more radical, and mysterious, than the one Benatar (2006; 2017) posits in his defense of anti-natalism. Benatar (i) treats each experience of pleasure (pain) symmetrically with other experiences of pleasure (pain) and (ii) allows that each are relevant to an agent's well-being. Most importantly, he provides a principled reason to treat pleasure and pain asymmetrically in the specific way he does by appealing to claims about what is in our interest at a time we've never existed compared to what is in our interest at a time we already exist. Bramble has no such explanation at his disposal. For an excellent, distinct, criticism of Benatar's position, see Bradley (2010).

6. We thank an anonymous referee for suggesting that we consider this sort of case. 
of our proposed dilemma after all.

Horn 2 - Symmetry: Suppose that Bramble opts to treat the two cases symmetrically $-\left(\mathrm{P}_{1}\right)$ is true but $\left(\mathrm{P}_{2}\right)$ is not, which is to say, just like purely repeated pleasures, purely repeated pains do not alter one's lifetime well-being. ${ }^{7}$ In this scenario, Bramble's view commits him to the implausible claim that continued life of eternal suffering can be just as good for a person as continued life of eternal pleasure. To illustrate, consider the following case.

Edie's Eternal Recurrence: Edie has lived 30 incredible years of life, filled with all the most diverse higher and lower pleasures one can imagineshe has travelled around the world, learned new languages, read Shakespeare, attended the opera, watched The Simpsons and Black Mirror, gone to parties with friends, eaten plenty of delicious foods, received compliments on her creative writing skills, and the list goes on and on. The following 30 years of Edie's life, however, were filled with torment, replete with the most horrific, diverse pains imaginable-her relatives and friends died slow, painful deaths; she has been robbed and assaulted; she was fired from her job; she has contracted various diseases; most of her hair fell out due to stress; a bird pooped on top of her bald head, and so on. Yet, when she turns 6o, Edie receives a visit from a powerful, magical being named Tina the Time Fairy, who controls time. Tina says that she can either make Edie re-experience the first 30 pleasurable years of her life exactly as it unfolded the first time with no even slightly qualitative differences over and over again ad infinitum, or she can make Edie re-experience the last 30 agonizing years of her life exactly as it unfolded the first time with no even slightly qualitative differences over and over again ad infinitum. ${ }^{8}$ Tina then asks which life Edie prefers. ${ }^{9}$

7. In a personal correspondence, Bramble opted for the second horn of the dilemma.

8. This is, of course, not eternal recurrence in the Nietzschean sense since it involves repetitions of subsets of one's life, rather than one's entire life (cf. Blumenfeld 2009). We are imagining that Edie's memory fades with time, such that at each moment she is re-experiencing some pleasure or pain, she has no recollection of having previously experienced that pleasure or pain.

9. This example is fantastical, though the same point may be illustrated with more realistic examples that concern finite amounts of pain and pleasure. Here is one. Suppose Edie is at a reception where servers are passing around bite-sized hors d'oeuvres, all of which are unfamiliar to Edie. She first tries a summer roll and hates it. It's one of the worst things she has ever eaten. She then tries a buffalo sprout and loves it. It's one of the most delicious things she has ever eaten. Now, both servers are headed Edie's way again. She is hungry and would like more to eat. She knows (i) that each item would be just as filling, (ii) that having another summer roll would perfectly duplicate the first experience she had eating one the first time around, and (iii) that having another buffalo sprout would perfectly duplicate the first experience she had eating one the first time around. What is the prudent choice for Edie? If Bramble opts for the second horn, according to his view, both options would be equally good for Edie. She should be indifferent between eating 
From a prudential standpoint, which option should Edie prefer? It seems quite clear that it is prudentially better for Edie to re-experience the first 30 years of her life that went wonderfully than to re-experience the last 30 years of her life that went horribly. Here's the problem for Bramble's view, however. Both options consist of sets of purely repeated pleasures or pains. Therefore, if we adopt the Non-Repetition Requirement and if Bramble accepts the second horn of our dilemma, then both options would be equally good for Edie. ${ }^{10}$ In other words, so long as Bramble opts to treat pains and pleasures symmetrically, neither option would add or detract any value from Edie's lifetime well-being. Edie should tell Tina that she has no preference and be indifferent between whatever choice Tina makes. But this is utterly absurd. The life of eternal pleasure would clearly be the better option for Edie. If there is one plausible axiom about well-being, it is that continued life of eternal suffering is worse for a person than continued life of eternal pleasure. So, in order to avoid this problem, Bramble needs to reject the Ron-Repetition Requirement.

This is especially unfortunate for Bramble because the purpose of adopting the Non-Repetition Requirement was to avoid the Porky problem. If Bramble rejects the Non-Repetition Requirement, his hedonism is susceptible to that objection again, which he regarded as too large a bullet to bite for hedonism. Now, we ask which is more reasonable: maintaining that Porky's life could be as good as a typical human's life, or holding that continued life of eternal suffering is as good as a life of eternal pleasure? We think it is clearly the former and we suspect that, if a committed hedonist were forced to choose between these two alternatives, she would agree with us. For that matter, we are quite confident that nonhedonists would agree with us too. The proposition that continued life of eternal suffering could be as good for a person as continued life of eternal pleasure is simply too implausible to regard as a viable option. Bramble's hedonism only achieves a pyrrhic victory if it avoids the Porky problem at the expense of incurring an even deeper problem.

\section{Conclusion}

In this paper, we aimed to demonstrate that there are very strong reasons to be suspicious of Bramble's Non-Repeatable Hedonism. At best, his view is deeply inchoate and is committed to absurd claims about which acts can maximize wellbeing. If Bramble maintains that purely repeated pleasures do not alter the value

the disgusting summer roll and the tasty buffalo sprout. This is an absurd conclusion. We thank an anonymous referee for raising this more realistic variant of Edie's Eternal Recurrence.

10. More precisely, neither option would be good or bad for Edie since neither option could contain any intrinsic goods or bads. 
of one's life considered as a whole, and that purely repeated pains do, then his account is committed to a mysterious unjustified asymmetry between pleasure and pain. Moreover, it entails that maximizing well-being requires preventing any quantity of repeated pain (no matter how small) over allowing any quantity of repeated pleasure (no matter how large). At worst, his view avoids the Porky problem at the expense of incurring a new, significantly worse, problem, viz., having to hold that continued life of infinite pain could be just as good for a person as continued life of infinite pleasure. These routes are untenable. The best route for Bramble is to either (I) reject the Non-Repetition Requirement and bite the bullet on the Porky problem or (II) reject hedonism altogether.

\section{References}

Benatar, David (2006). Better Never to Have Been: The Harm of Coming into Existence. Oxford University Press. https://doi.org/10.1093/acprof:oso/9780199296422.001.0001

Benatar, David (2017). The Human Predicament: A Candid Guide to Life's Biggest Questions. Oxford University Press. https://doi.org/10.1093/acprof:o so/9780190633813.001.0001

Blumenfeld, David (2009). Living Life Over Again. Philosophy and Phenomenological Research, 79(2), 357-386. https://doi.org/10.1111/j.1933-1592.2009.00282.x

Bradley, Ben (2010). Benatar and the Logic of Betterness. Journal of Ethics and Social Philosophy, 4(2), 1-6. https://doi.org/10.26556/jesp.v4i2.133

Bramble, Ben. (2013). The Distinctive Feeling Theory of Pleasure. Philosophical Studies, 162(2), 201-217. https://doi.org/10.1007/s11098-011-9755-9

Bramble, Ben (2015a). Consequentialism about Meaning in Life. Utilitas, 27(4), 445-459. https://doi.org/10.1017/S095382081500014X

Bramble, Ben (2015b). The Role of Pleasure in Well-Being. In Guy Fletcher (Ed.), The Routledge Handbook of Philosophy of Well-Being (109-208). Routledge.

Bramble, Ben, (2016). A New Defense of Hedonism about Well-Being. Ergo, 3(4), 85-112. https://doi.org/10.3998/ergo.12405314.0003.004

Bramble, Ben (2018). The Passing of Temporal Well-Being. Routledge. https://doi. org/10.4324/9781315213385

Feldman, Fred (2004). Pleasure and the Good Life. Oxford University Press. https://doi. org/10.1093/019926516X.001.0001

Fischer, John Martin (1997). Death, Badness, and the Impossibility of Experience. The Journal of Ethics, 1(4), 341-353. https://doi.org/10.1023/A:1009771331402

McMahan, Jeff (1988). Death and the Value of Life. Ethics, 99(1), 32-61. https://doi. org/10.1086/293034 
